\title{
História cultural, linguagem fílmica e ditadura militar brasileira
}

\author{
Cultural history, film language and Brazilian military dictatorship \\ Historia cultural, lenguaje cinematográfico y dictadura militar brasileña
}

Igor Barbosa Cardoso ${ }^{1 *}$

${ }^{1}$ Universidade Federal de Minas Gerais, Belo Horizonte/MG - Brasil

Dellamore, Carolina; Amato, Gabriel; BaTISTA, Natalia (orgs.). A ditadura na tela: o cinema documentário e as memórias do regime militar brasileiro. Belo Horizonte: Faculdade de Filosofia e Ciências Humanas, 2018.

Há algumas décadas, os estudos culturais flexibilizaram uma tradição de estudos históricos a fim de refletir sobre as políticas de identidade que discutem a questáo do sujeito a partir de conflitos sociais em que há afirmação ou negação de identidades étnicas, nacionais, etárias, de gênero, de classe e outras. A renovação dos estudos históricos impactou as análises fílmicas no sentido de superar o diagnóstico estrutural da produção cultural de massa para voltar o olhar às condiçóes efetivas e específicas de produção e recepção da obra. O olhar histórico e sociológico tendo o cinema como fonte de pesquisa passou a privilegiar, quando muito, o nível narrativo-dramático, em detrimento dos componentes propriamente estéticos.
Sob a organização dos doutorandos Carolina Dellamore, Gabriel Amato e Natalia Batista, o livro A ditadura na tela procura equilibrar as análises oriundas dos estudos culturais, levando em consideração a linguagem cinematográfica, em uma articulação interdisciplinar. Logo na introdução ("A ditadura na tela: questôes conceituais") - escrita pelos organizadores -, três pressupostos orientam a curadoria: os filmes documentais são tratados como "trabalhos de recordação interessados na construçáo de identidades e de projetos políticos no tempo presente de sua produção" (p. 12); são previamente indexados de modo que pactuam com o espectador um "compromisso de exploração da realidade" (p. 13); e são resultados de uma conformação cultural atual que demanda narrativas memorialísticas. A partir desses pressupostos, os historiadores articulam alguns com mais sucesso - elementos fílmicos e extrafílmicos para compreender os posicionamentos assumidos pelos diretores em

DOI: http://dx.doi.org/10.1590/2237-101X02104312.

Resenha recebida em 19 de dezembro de 2018 e aceita para publicação em 28 de maio de 2019.

* Doutor pela Universidade Federal de Minas Gerais / Departamento de História, Belo Horizonte/MG Brasil. E-mail: igorbcardoso@gmail.com. ORCID: https://orcid.org/0000-0002-2460-2693. 
seus trabalhos bem como a relação de suas obras com o público.

A ditadura na tela é fruto do projeto de extensão, de título homônimo, conduzido pelo Núcleo de História Oral da UFMG. Em parceria com equipamentos públicos de Belo Horizonte - Centro de Referência da Moda e Museu da Imagem e do Som (MIS) Cine Santa Tereza -, o projeto exibiu, entre 2014 e 2017, diversos documentários a respeito do período ditatorial brasileiro (1964-1985), seguidos de discussóes fomentadas por pesquisadores convidados. O livro é constituído de duas partes. A primeira ("As batalhas de memória no cinema documentário sobre a ditadura") é resultado da reuniáo de dez artigos oriundos dessas intervençôes públicas. Em parte por isso, não é possível encontrar unicidade metodológica de análise. Os temas abordados também são diversos: a militância de mulheres, estudantes universitários e operários; a relação entre Estado, futebol e imprensa; na produção cultural, a literatura de temática lésbica de Cassandra Rios, o grupo inovador Dzi Croquettes, o movimento (musical) tropicalista e os silêncios sobre o cantor Wilson Simonal.

Juliana Ventura Fernandes analisa $R e$ pare bem (2012), documentário da cineasta portuguesa Maria de Medeiros. No artigo, alguns aspectos próprios da composição fílmica são abordados, tais como a construção cênica (locaçôes quase sempre na casa das entrevistadas), a montagem (que faz coincidir a fala das entrevistadas com imagens documentais, reforçando o argumento apresentado) e, especialmente, a oralidade (considerando tanto os momentos de maior contundência do discurso, quanto os depoimentos mais fragmentários e fugidios, além dos silêncios e pausas). A análise da violência e da perseguição política pelas quais três geraçóes de mulheres foram submetidas, proposta de Medeiros, é compreendida por Fernandes no campo das estratégias estatais de construçấo de uma memória sobre a ditadura, uma vez que o documentário é fruto da iniciativa do projeto Marcas da Memória, que tem por finalidade construir alternativas à atuação dos órgáos oficiais de reparação - geralmente, de caráter pecuniário - ao fornecer material para o reconhecimento de experiências de violência durante a ditadura.

De modo relativamente semelhante, Gabriel Amato analisa Memória do movimento estudantil (2007), documentário dirigido por Silvio Tendler, relacionando os elementos propriamente fílmicos e o debate historiográfico sobre a União Nacional dos Estudantes (UNE), entidade que financiou a produçáo documental por meio de Lei Federal de Incentivo à Cultura. A partir do conceito exposto por Marie-Claire Lavabre, de que a memória histórica é uma sobreposição das fronteiras entre a prática social da memória e a atividade intelectual historiográfica, Amato propóe que a estética realista de Tendler corrobora a narrativa hegemônica sobre o movimento estudantil desenvolvida em $O$ poder jovem (1968), de Arthur Poerner, segundo o qual "o estudante brasileiro é um oposicionista nato” (p. 56). Amato explora com acuidade o recorte realizado pelo documentarista dos documentos de época, das trilhas sonoras não originais, dos acontecimentos, das personagens e das 
entrevistas. Segundo o articulista, a seleção prévia expressa determinada visão de mundo que acaba por reduzir "a participação política dos estudantes brasileiros à história da UNE e a determinado modelo de militância dentro da entidade" (p. 59). Com efeito, a contracultura e o hippismo, duas manifestaçôes culturais caras à juventude das décadas de 1960 a 80, permanecem silenciadas face à memória histórica da UNE - o que se reflete no trabalho de Tendler.

Também encontramos boa discussão historiográfica e de linguagem fílmica com Davi Aroeira Kacowicz, que analisa Tropicália (2012), documentário dirigido por Marcelo Machado. Como Amato sugeriu em relação a Memórias do movimento estudantil, Kacowicz discute a reprodução de certa memória histórica sobre a efervescência cultural dos anos 1960 no documentário de Machado, qual seja a de que a tropicália, conceito estético que designou uma constelação de vanguardas culturais, acaba reduzido ao tropicalismo, movimento musical de Gilberto Gil, Caetano Veloso, Torquato Neto e tantos outros. Em contrapartida, Kacowicz evidencia que a historiografia mais recente compreende a contracultura brasileira para além das fronteiras da cena musical, a exemplo dos importantes trabalhos de Frederico Coelho (Eu, brasileiro, confesso minha culpa e meu pecado, 2010), de Christopher Dunn (Brutalidade jardim, 2009) e de Heloísa Buarque de Hollanda (Impressóes de viagem, 2004). Apesar disso, o artigo aponta que o levantamento documental empreendido por Machado traz fatos inéditos que podem revisar em parte a discussão historiográfica, como as cenas do Festival da Ilha de Wight de 1970 e a versão ao vivo da faixa Alfômega, apresentada por Caetano e Gil na rede de televisão portuguesa em 1969. Além da raridade material, Kacowicz atenta para o cuidadoso trabalho dispensado em Tropicália na condução da trilha sonora (sugerindo haver um refinamento técnico das músicas), dos efeitos de pós-produção (com inserçáo de cores vivas nas imagens em $\mathrm{p} \& \mathrm{~b}$ ) e de montagem, capazes de envolver o público em um "painel imagético-sonoro do contexto" (p. 133).

Da mesma forma que Kacowicz acredita que Tropicália pode contribuir para novas questóes ao debate historiográfico, Natália Batista defende a tese de que o documentário Dzi Croquettes (2009), de Tatiana Issa e Raphael Alvarez, inaugurou uma discussáo que ainda não havia sido feita pelos historiadores, isto é, o papel do teatro na resistência à ditadura pelo viés do escracho e do humor, com a abordagem das homossexualidades. Batista também explicita que o esquecimento/apagamento em torno do grupo teatral dificulta a construção documentária na falta de outras ancoragens narrativas. De todo modo, por meio de entrevistas, imagens de arquivo e trilha sonora, Batista acredita que Issa e Alvarez conferem uma dimensão de engajamento do grupo diante da ditadura e um reconhecimento de sua importância tanto no âmbito nacional quanto no internacional. Ademais, segundo Batista, o documentário permite questionar o pressuposto de "vazio cultural dos anos 1970" e, em especial, o papel dos corpos como atos políticos. 
Ana Marília Menezes Carneiro debate a questão de gênero a partir de Cassandra Rios: a Safo de Perdizes (2013), documentário dirigido por Hannah Korich que conta com depoimentos de familiares, estudiosos e pessoas próximas da escritora, que escreveu romances bastante populares com temáticas homoeróticas. Carneiro ressalta a importância do documentário por reapresentar Cassandra Rios para além dos estereótipos muitas vezes preconceituosos e, ainda, por levar em consideraçáo o amplo alcance de público, expressão de uma demanda social latente pelos temas ficcionalizados pela escritora. Apesar da boa discussão mobilizada por Carneiro em torno do silenciamento midiático sobre Cassandra Rios - reproduzindo em parte o argumento apresentado no depoimento de Laura Bacelar, editora de grande parte dos romances de Rios -, talvez fosse interessante resgatar reportagens de época em importantes meios de comunicação a fim de melhor explorar - e quem sabe nuançar - a tese sobre a recepção de suas obras durante a década de 1970, a exemplo do perfil elaborado sobre Cassandra Rios pela revista Realidade em 1970 e da crítica ao romance Carne em delírio escrita por Marina Colasanti e publicada pelo Jornal do Brasil em 1972.

Como no artigo de Juliana Ventura, a participação de mulheres na resistência à ditadura também é tema discutido por Débora Raiza Carolina Rocha Silva, que analisa Que bom te ver viva, documentário dirigido por Lúcia Murat e lançado em 1989. Silva retoma o contexto de produçáo memorialística e historiográfica sobre a ditadura militar nos finais da década de 1980 para compreender a representação do feminino na obra de Murat, em especial no que diz respeito à tortura de cunho sexual contra mulheres. Também lança um olhar atento sobre a recepção da obra no meio midiático. $\mathrm{O}$ artigo não explora o estatuto do documentário de Murat, constituído de cenas dramatizadas e depoimentos, o que poderia enriquecer enormemente a análise sobre as fronteiras do dizível, uma vez que a ficção é aí elemento central na abordagem de um tema sensível.

$\mathrm{O}$ artigo de Isabel Cristina Leite da Silva também aborda a representaçáo do feminino durante a ditadura. Analisa Subversivas - Retratos femininos de luta contra a ditadura (2013), documentário dirigido por Fernanda Vidigal e Janaina Patrocínio. O texto destaca a inclusão de novos temas pelo documentário para compreender o período da ditadura militar, como o de conciliaçáo entre o mundo político e o mundo privado, a maternidade, a revoluçáo sexual e os novos comportamentos por parte de setores da sociedade brasileira frente ao aborto. A leitura realizada pela autora privilegia a exposição da narrativa desenvolvida pelo documentário, sem colocar questóes com relaçáo à linguagem propriamente fílmica.

A partir de Simonal-ninguém sabe o duro que dei (2009), documentário dirigido por Cláudio Manoel, Micael Langer e Calvito Leal, Bruno Vinicius de Morais tematiza o corpo negro do cantor Wilson Simonal como parte de uma memória subterrânea sobre o período ditatorial. Por meio de entrevistas concedidas por Manoel, que também foi comediante do grupo global Casseta 
\& Planeta, Morais identifica um projeto de releitura sobre o período ditatorial brasileiro pretensamente assentado na renovaçáo historiográfica empreendida por Daniel Aarão Reis Filho, para quem os anos de chumbo foram de relativo consenso e legitimação social, sendo que as esquerdas não apresentavam até então um programa democrático face ao autoritarismo de direita. Morais avalia que a forma pela qual o documentário foi recebido pela opinião pública em jornais e revistas é significativa: em geral, Wilson Simonal é representado como um artista ingênuo e apolítico; por outro lado, a esquerda é associada a um "stalinismo midiático", táo autoritária quanto a própria ditadura. Segundo Morais, a apreensão conservadora sobre o regime militar acaba por se silenciar acerca de outras questốes caras à trajetória do cantor, como as denúncias que fazia contra o racismo e a afirmação do orgulho negro em plena década de 1960, quando o debate racial carecia de espaços institucionalizados.

Já o artigo de Carolina Dellamore versa sobre Greve! (1979), documentário de João Batista de Andrade, que registrou o movimento grevista dos metalúrgicos em Sáo Bernardo do Campo (SP). Para Dellamore, o cineasta não somente mostrou a greve, mas buscou especialmente intervir na realidade, na medida em que o que ele filmou foi a situação criada a partir da presença da câmera, o que Jean-Claude Bernadet denominou de "dramaturgia da intervençáo" (p. 87). $\mathrm{O}$ artigo explora a narrativa em off, que muitas vezes chega a ser irônica se contrapondo à exibição das imagens e às falas dos entrevistados. Outro aspecto da construção narrativa evidenciada por Dellamore reside na montagem empreendida por Andrade, que faz o depoimento do interventor Guaracy Horta em defesa da "normalidade" nos sindicatos ser contradito pelas imagens de repressão policial sobre os trabalhadores nas ruas. A trilha sonora, com músicas de Belchior, também é explorada como elemento diegético que sugere por vezes ambiguidade com relaçáo às imagens exibidas. $\mathrm{O}$ movimento de câmara é analisado ao final, quando o cineasta privilegia a perspectiva do operário em vez do ponto de vista do palanque, das lideranças, revelando a posição crítica de desconfiança assumida por Andrade.

Marcus Vinícius Costa Lage escreve sobre Memórias do chumbo: o futebol nos tempos do Condor (2012), uma série de quatro documentários realizada por Lúcio de Castro sobre o uso político do futebol pelas ditaduras militares de Argentina, Brasil, Chile e Uruguai. Exibida pelo canal televisivo ESPN Brasil, a série é analisada por Lage a partir da construçáo narrativa, ora atentando-se para a composição da trilha sonora, ora para os cenários nos quais os entrevistados depóem sobre o tema. Segundo o articulista, a abordagem escolhida por Castro privilegia a denúncia contra a corrupçáo das entidades desportivas, que seriam caracterizadas pela manipulação da opinião pública por meio do futebol, com interferência direta dos governos autoritários. O contexto de produção e lançamento da série - isto é, seis meses antes da realização da Copa das Confederações da FIFA no Brasil, quando parte da imprensa discutia a promoçáo de megaeventos esportivos que demandaram vulto- 
so financiamento estatal - ajuda a explicar, segundo Lage, o posicionamento crítico do cineasta bem como do canal televisivo.

$\mathrm{Na}$ segunda parte do livro ("O fazer e o guardar no campo do cinema documentário sobre a ditadura"), a cineasta e professora Anita Leandro (UFRJ) escreve sobre o método de "montagem direta" utilizado em seu documentário Retratos de identificação, que consiste no comparecimento da imagem de arquivos - muitas delas inéditas e produzidas pela polícia para fins de identificação e controle do prisioneiro - diante da testemunha. Segundo a autora, o método precede a montagem propriamente dita de modo que de entrevistada a testemunha torna-se narradora de uma história na primeira pessoa. Apesar de existir uma seleção prévia das imagens e uma ordem de apresentação que designam um roteiro, a metodologia de Anita Leandro possibilita um novo campo de pesquisa ao despertar a potência mnêmica dos materiais de arquivo com a fala das testemunhas. Ainda com relação à segunda parte do livro, Marcella Furtado faz um apanhado geral sobre o acervo do MIS de Belo Horizonte, composto basicamente por cinejornais institucionais produzidos pela prefeitura e por materiais brutos e editados pela TV Globo Minas.

Por fim, vale ressaltar que o livro $A$ ditadura na tela se mostra relevante para o atual debate historiográfico por diversos motivos. Em primeiro lugar, a própria seleção dos do- cumentários privilegia a inclusão de novos sujeitos - mulheres, negros, homossexuais para a compreensão mais plural da ditadura militar brasileira, que por vezes é centrada pela atuação de partidos e lideranças políticas. Em segundo lugar, no caso dos documentários que abordam atores já consagrados tanto pela memória quanto pela historiografia, como no caso da atuaçáo do movimento estudantil ligado à UNE, o tratamento analítico dos articulistas procura explorar os desvios em relação às narrativas hegemônicas. Por fim e em terceiro lugar, ainda que nem todos os artigos se debrucem mais detidamente sobre a linguagem fílmica, fica nítido o esforço de levar em consideração tanto os elementos de produção e recepção das obras quanto os elementos estéticos específicos de fontes audiovisuais. Em tempo de revisōes grosseiras sobre o período, $A$ ditadura na tela contribui para um debate público qualificado, ultrapassando a interlocução entre pares, algo cada vez mais necessário.

\section{Referência}

DELLAMORE, Carolina; AMATO, Gabriel; BATISTA, Natalia (orgs.). A ditadura na tela: o cinema documentário e as memórias do regime militar brasileiro. Belo Horizonte: Faculdade de Filosofia e Ciências Humanas, 2018. 